\title{
The Place of Mother Tongue in Foreign Language Classes
}

\begin{abstract}
Mustafa ŞEVIIK*
ABSTRACT: There are various opinions about using students' mother tongue in foreign language classes. While most of the foreign language teaching methods suggest that only the target language should be used in foreign language classes, the others suggest that mother tongue can aid in the teaching of modern foreign languages. The recent studies on the subject reveal that a judicious and limited use of mother tongue is necessary and has a facilitating role in the teaching of modern foreign languages. The subject of this study is whether Turkish should be used in English langauge classes and the reasons for this. The views of foreign language teachers and students are taken. A total of 10 English language teachers and 148, 9th grade students participated in the study. The study was carried out by administering a questionnaire at the end of the second term of the academic year. The data obtained from the study show that most of the teachers and students are not against mother tongue, and that mother tongue contributes to language learning towards various aims and at different levels. As a result, it is suggested that being conscious about the subject and making use of the positive effects of the mother tongue is a better attitude than being totally against the use of mother tongue.

Key words: Modern Foreign Language, Mother Tongue, Teaching
\end{abstract}

* Assist.Prof.Dr. Mehmet Akif Ersoy University, Faculty of Education, msevik@mehmetakif.edu.tr 


\section{SUMMARY}

Introduction: Using mother tongue in foreign language (FL) classes has long been seen as a taboo both by foreign language teachers and by researchers. The main reason for this is the theoretical underpinnings of FL approaches and methods. The two main aproaches which determine the extent to which mother tongue should be used in FL classes are; monolingual and bilingual approaches. As can be understood from the terms, the monolingual approach suggests that the only medium of in-class communication should be the target language but nothing else. Whereas the bilingual approach suggests that mother tongue can and should be used to certain extents in FL classes. Deller and Rinvolucri (2002) claim that there has been a shift in FL methodologies recently, and that the mother tongue is indeed "the mother" of a second, third or fourth language. They favour using mother tongue in FL classes in clearly defined situations and with carefully chosen activities. There are also some other scholars (names mentioned in the body of the article) who suggest that the monolongial approach has lost its appeal especially in the past 15 years. Another dimension for the subject is raised by Nunan and Lamb (1996) when they suggest that FL teachers who teach at beginner levels find it practically impossible to ban mother tongue altogether from FL classes. It is also suggested that mother tongue can aid and ease the teaching of FLs. Under the light of such scenerios FL teachers and researchers have started to re-examine the role of mother tongue and to explore how mother tongue can be effectively used in FL classes.

There is actually an extensive literature about when and how mother tongue can be used in FL classes. The mostly written and met situations are; with beginners to encourage participation and motivation, to aid vocabulary learning, while checking for listening and reading comprehension, and when teaching complex grammatical points. There are also many research on teacher and student attitudes towards using mother tongue in FL classes. Schweers (2003), for example, carried out a research in a Spanish context and found out that most of the FL teachers and students agree on using Spanish in English language classes. In a similar study carried out earlier by Tang (2002) in a Chinese context, it is also found out that teachers and students favour using Chinese in English language classes.

Method: Participants of this study were 148 (secondary school) $9^{\text {th }}$ grade FL students and 10 English language teachers. The students' levels of English were lower-intermediate and the teachers' professional experiences ranged from 5 to 15 years. A questionnaire was administered to students (Appendix 1) and to teachers (Appendix 2) at the end of the second term, 
and the return rate was $\% 100$. The SPSS 11 Programme was used and the final data were obtained through descriptive analysis. The study aims to find out answers for: 1- Should Turkish be used in FL classes? If so, how frequent and why? 2- What are the beliefs and attitudes of students and teachers about using Turkish in FL classes?

Results: Research findings show that $\% 70(\mathrm{f}=7)$ of the teachers and $\% 69(\mathrm{f}=102)$ of the students think Turkish should be used in English language classes. \%98.6 $(\mathrm{f}=146)$ of the students think that Turkish should be used at various frequencies, the most being 'sometimes' with \%66.9 (f=99). Research findings show that for both teachers $(\% 80 / \mathrm{f}=8)$ and students $(\% 91.8 / \mathrm{f}=136)$ 'the teaching of complex grammar points' is where Turkish should be mostly used. \%95.9 ( $\mathrm{f}=142)$ of the students stated that Turhish helps them to understand difficult subjects, and $\% 70(\mathrm{f}=7)$ of the teachers stated that they use Turkish because they think it helps a great deal in students' understanding. \%96.6 ( $\mathrm{f}=143$ ) of the students think that Turkish helps their understanding at various levels, the most being 'sometimes' with $\% 48.6(\mathrm{f}=72)$.

Conclusion: The findings of this study demonstrated that a logical and limited use of mother tongue in FL classes does not reduce students' exposure to English, on the contrary it may have a facilitating and helping role in the learning and teaching process. Eventhough a great majority of the teachers and students who participated in this study stated that Turkish should be used in FL classes, this should not suggest an overuse of the mother tongue. Depending on the findings of the study, it is possible to argue that the main reasons and the most effective ways of using mother tongue in FL classes can be: - in teaching complex grammar points, - in understanding some words and expressions better and teaching meaning, - especially when the beginner level students are at stake, it is almost practically impossible to ban mother tongue, - as mother tongue facilitates and helps understanding and learning, and - as it saves time. A question raised by the study is whether a bilingual approach can be effective in course books. There are various advantages to this as argued by Jin (2003), however this is something educators and policy makers should be sceptical about even before taking any measures. Therefore, further research needs to be carried out in order to find out whether such an approach can aid language learning. 


\title{
Yabancı Dil Sınıflarında Anadilin Yeri
}

\begin{abstract}
Mustafa SEVIKK*
ÖZ: Yabancı dil sınıflarında öğrencilerin anadillerinin kullanılıp, kullanılmaması gerektiği konusunda farklı görüşler bulunmaktadır. Yabancı dil öğretim metotlarının birçoğu sınıf içerisinde sadece hedef dilin kullanılması gerektiği fikrini savunurken, diğerleri ise anadilin yabancı dil öğretimine katkıda bulunabileceği görüşünü savunmaktadır. Özellikle son yıllarda, konu hakkında yapılan araştırmalar bilinçli ve limitli anadil kullanımının yabancı dil öğretiminde gerekli ve kolaylaştırıcı bir rolü olduğu görüşünü ortaya koymaktadır. Bu çalışmada, Türkçe'nin İngilizce derslerinde kullanılıp, kullanılmaması gerektiği ve bunun nedenleri konu edilerek yabanc1 dil öğretmenlerinin ve öğrencilerinin görüşlerine bașvurulmuștur. Calıșmaya toplam 10 İngilizce öğretmeni ve 148, 9. sınıf öğrencisi katılmıştır. Çalışma eğitim öğretim yılının ikinci döneminin sonunda uygulanan bir anketle yapılmıștır. Çalışmadan elde edilen veriler öğretmen ve ögrencilerin çoğunluğunun anadil kullanımına karşı olmadıklarını, anadil kullanımının faklı hedefler doğrultusunda ve farklı seviyelerde yabancı dil öğrenimine katkıda bulunduğunu düşündüklerini bildirmişlerdir. Sonuç olarak, anadil kullanımına tamamen karşı bir tutum sergilemektense, konu hakkında bilinçli olunmasının ve belli durumlarda anadilin olumlu etkilerinden faydalanılmasının daha yerinde olacağı görüşü benimsenmiştir.
\end{abstract}

Anahtar Sözcükler: Yabancı dil, Anadil, Öğretim

*Yrd.Doç.Dr. Mehmet Akif Ersoy Üniversitesi Eğitim Fakültesi msevik@mehemetakif.edu.tr 


\section{GíRIŞ}

Yabancı dil sınıflarında anadilin yeri ne olmalıdır konusu, yabancı dil eğitimcileri ve öğretmenleri arasında öyle bir tabu haline gelmiştir ki, kimse bu konu hakkında fazlaca konuşmak istemez. Yabancı dil öğretmenleri sınıfta farklı aralıklarla ve farklı amaçlar doğrultusunda Türkçe kullanır ancak bunu birbirlerine söylemekten kaçınır. Araştırmacılar ise genelde böyle bir konu hakkında araştırma yapmaktan kaçınır. Peki, anadilin bir tabu haline gelmesinin nedenleri nelerdir? Bunun en temel nedenlerinden birisi bizlere üniversite hayatımız boyunca aktarılan ve şimdi ise bizlerin öğrencilerimize aktardığı yabancı dil öğretim metotlarının prensipleridir. Birçoğumuza, hedef dildeki bilinmeyen kelime anlamlarını hedef dilde açıklamamız gerektiği ve derslerde sadece hedef dil kullanmamız gerektiği öğretilmiştir. Eğer anadil kullanılırsa yabancı dil öğretiminin yanlış olacağ 1 ve öğrencilerin istenmeyen davranışlar edineceği söylenerek, anadil kullanımı zaman zaman şiddetle yasaklanmıştır. Hatta yabancı dil derslerinde anadillerini kullanan öğrenciler sembolik para cezalarına bile çarptırılmışlardır. Birçoğumuz aldığı eğitim boyunca bu ve benzeri durumlarla karşılaşmış olabilir. Elbette, bu araştırmanın bizlere öğretilenlerin ve şimdi ise bizlerin öğrettiklerimizin tamamen yanlış veya yersiz olduğu gibi bir iddiası yoktur. Bu nedenle öncelikle, herkes tarafından kabul edilmiş ve yabancı dil öğretim yöntemleri araştırmalarına her zaman 1şık tutmuş olan yabancı dil öğretim metotlarının konu hakkındaki ilkelerine yer vermek yerinde ve olumlu bir adım olacaktır:

Tablo 1: Yabancı Dil Öğretim Metotları ve Anadil

\begin{tabular}{|c|c|}
\hline Yabancı Dil Ö̆̆retim Metotları & Anadil Kullanımı \\
\hline The Grammar Translation Method & Evet Kullanılmalı (yoğun olarak) \\
\hline The Direct Method & Asla Kullanılmamalı \\
\hline The Oral Approach & Asla Kullanılmamalı \\
\hline The Audiolingual Method & Asla Kullanılmamalı \\
\hline Communicative Language Teaching & Limitli ve mantıklı kullanılmalı \\
\hline Total Physical Response & Asla Kullanılmamalı \\
\hline Community Language Learning & Limitli ve mantıklı kullanılmalı \\
\hline The Natural Approach & Asla Kullanılmamalı \\
\hline
\end{tabular}

Kaynak: Richards\&Rodgers, 1995

Tablo 1'de görüldüğü üzere 8 yabancı dil metodunun 6 tanesi anadili sınıflarda yasaklamış, 2 tanesi limitli ve mantıklı kullanım önermiş ve 1 tanesi ise yoğun anadil kullanımını ilke olarak belirlemiştir. Anadil kullanımını yasaklayan metotların hareket noktası tek dilli yaklaşım 
(monolingual approaches) adı verilen felsefedir. Bu felsefe hedef dilin, sinif içi iletişim dili olması gerektiğini savunur ve ana dil kullanımının sınıf içerisinde yasaklanmasının hedef dildeki öğrenme etkililiğini en üst seviyeye çıkaracağı fikrini kabul eder. Tek dilli yaklaşımın savunucularından biri olan Krashen (1981), yabancı dil öğrenen insanların ana dil edinim süreciyle tamamen aynı bir süreçten geçtiklerini, dolayısıyla da yabancı dil öğrenimi aşamasında ana dilin en alt seviyede tutulması gerektiği fikrini savunur.

Anadil kullanımını belli ölçülerde de olsa benimseyen metotların temelinde ise iki dilli yaklaşım (bilingual approaches) adı verilen felsefe yatmaktadır. Deller ve Rinvolucri'ye göre (2002) yabancı dil öğretim yaklaşımlarında bir değişim sürecine girilmiştir. Geçtiğimiz son 40 yılda Amerika'da, İngiltere'de ve Avrupa'da hakim olan düşüncenin tersine, Deller ve Rinvolucri aslında anadilin ikinci, üçüncü ve hatta dördüncü dillerin de anası olduğu görüşünü ortaya atmaktadır. Öğrencilerin zihninde, yeni diller bu kaynaktan beslenerek üreme gösterirler, öyleyse anadili yabancı dil sınıflarından uzak tutmak tıpkı bir bebeğin doğduğu ilk gün anne sütünden ayrılması gibidir. Yaptıkları araştırmaların sonucunda, anadili açıkça tanımlanmış durumlarda ve dikkatlice seçilmiş aktiviteler eşliğinde kullanmamız gerektiğini tavsiye etmektedirler (Deller ve Rinvolucri, 2002). $\mathrm{Bu}$ düşüncelerinin temelinde öğrencilerin zaman içerisinde anadile olan bağımlılıklarının kendiliğinden azalacağı görüşü hakimdir. Anadilin mantıklı bir şekilde kullanılmasının hem öğrencilerin hem de öğretmenlerin lehinde olacağını ortaya koymaktadırlar. Benzer görüşleri savunan bir diğer araştırmacı olan Tang (2002), özellikle son 15 yıldaki sürece göz atılacak olursa tek dilli yaklaşımların cazibesini yitirdiğini ileri sürmektedir. Medgyes'de (1994) tek dilli felsefenin "ister psikolojik, ister dilbilimsel isterse de pedagojik olsun, hiçbir zeminde savunulamaz olduğunu" kabul eder. Anadilin tamamen göz ardı edilmesinin anadili eleştirmek ve anadili ikinci sınıf dil olarak görmek anlamına geldiği yönünde eleştiriler bulunmaktadır. Anadilin bu şekilde alçaltılması öğrenciler üzerinde zararlı psikolojik etkilere bile neden olabilmektedir (Nation, 1990).

Özellikle geçtiğimiz 20 yılda, ikinci dil edinim süreci üzerine araştırma yapan bilim adamları, anadilin yabancı dil sınıflarındaki rolünün önemini fark etmişlerdir. Örneğin, Nunan ve Lamb (1996), yaptıkları bir araştırmada, alt seviyeli İngilizce bilgisine sahip tek dil bilen öğrencilere yabancı dil öğreten öğretmenlerin, sınıf içerisinde anadilin yasaklanmasının pratik olarak mümkün olamayacağı görüşünde olduklarını tespit etmişlerdir. $\mathrm{Bu}$ durumda anadil kullanımını yasaklayan yaklaşımların ne derecede güvenilir ve uygulanabilir oldukları tartışılması gereken bir konudur. Anadilin, hedef dildeki iletişim eksikliklerinin giderilmesi amaciyla kullanıldığı da saptanmıştır (Dörnyei ve Kormos, 1998). 
Jin'in (2003) öne sürdüğü gibi özellikle son on yıldır Batı dünyasında yapılan eğitim araştırmalarının en göze çarpan konularından birisi iki dilli (bilingual) yabancı dil eğitimidir ve bu görüş öğrencilerin anadillerinin, ikinci dil veya yabancı dil öğretimini kolaylaştırdığı savını temel almaktadır. Alanda yapılan birçok araştırma ve geliştirilen iki dilli öğretim programları, yabancı dil öğretim yöntemlerinde yeni bir çağ açılmasına öncülük ederek anadilin yabancı dil öğretimindeki olumlu rolünü ortaya çıkarmıştır. $\mathrm{Bu}$ senaryolar ışığında araştırmacılar ve yabancı dil öğretmenleri anadilin rolünü tekrar gözden geçirmeye başlamışlar ve anadili yabancı dil öğretimine en iyi şekilde nasıl adapte edebileceklerinin yollarını aramaya koyulmuşlardır (Rinvolucri, 2001).

Auerbuch (1993) ise, yabancı dil sinıflarında anadil kullanılmasının öğrencilere güven verdiğini ve öğrencilerin deneyimlerini dikkate alarak kendilerini ifade etme özgürlüğüne olanak sağladığı görüşünü savunmuştur. Güven duygusu kazanan öğrenciler yabancı dille deney yapmaya ve risk almaya daha istekli bir tutum içerisine girerler. Bireylerin benlik duyguları anadilleri ile iç içedir ve şayet öğrencilerden anadillerini tamamen göz ardı etmeleri istenecek olursa, öğrenciler benlik duygularının tehdit edildiği hissine kapılarak yabancı dile karşı olumsuz bir tavır içine girebilirler. $\mathrm{Bu}$ durum bir yabanc1 dil öğretmeninin isteyebileceği son şeydir. Auerbuch (1993: 23), konuyu bir adım daha öteye taşıyarak yabancı dil sınıflarında anadilin kullanılabileceği alanları 8 ana başlık altında toplamıştır:

- Kelimelerin anlamlarının kavranması

- Öğrencilerin anlama düzeylerinin kontrol edilmesi (okuma ve dinlemeden sonra)

- Karmaşık konular hakkında bilgilendirme yaparken

- Grup çalışması yaparken

- Temel seviyede ders metodolojisi hakkında bilgi verirken

- Yeni öğretilen dil konusunu kontrol etmek için çeviri yönteminin kullanilmasi

- Öğrenciler hedef dilde anlamsız cümleler kurduğunda

- Sinav amaçlı (testing)

Deller ve Rinvolucri'de (2002:117), yabanc1 dil siniflarında anadilin kullanılabileceği yerleri açıkça tanımlamakta ve sadece belli durumlar söz konusu olduğunda kullanım tavsiye etmektedirler, örneğin;

- Hedef dildeki dilbilgisi kurallarının anadil kuralları ile karşılaştırılması bazı öğrenciler üzerinde çok olumlu etkiler yaratabilir 
- Sınıf içinde anadil kullanılmasına izin verilirse dil öğrenmeye yeni başlamış olan öğrenciler muhtemelen daha çabuk ilerleme gösterecektir

- Öğrencilere sorun yaratan dilbilgisi kuralları varsa çeviri alıştırmaları en iyi uygulama olabilir

$\mathrm{Bu}$ noktaya kadar genelde teorik görüşlerden bahsedildi. Oysa konu hakkında farklı zeminlerde yapılmış olan birçok araştırma bulunmaktadır. Uygulama bazında öğrenci ve öğretmen görüşlerinin karşılaştırılıp tartışılabilmesi için, bu araştırmalardan bazılarına yer vermek uygun olacaktır. Örneğin, Schweers (2003) İspanya'daki yabancı dil öğrencilerinin ve öğretmenlerinin, yabancı dil sınıflarında anadilin kullanılması konusuna yönelik tutumlarını araştıran bir çalışma gerçekleştirmiştir. Bulgular gerek öğrencilerin gerekse öğretmenlerin büyük bir çoğunluğunun yabanc1 dil sınıflarında İspanyolca kullanılması konusunda hemfikir olduklarını göstermektedir(bkz. Ek-3). Benzer bir araştırmada, Tang (2002) Çin'deki yabanc1 dil öğrencilerinin ve öğretmenlerinin, yabanc1 dil sinıflarında anadilin kullanılması konusuna yönelik tutumlarını araştıran bir çalışma gerçekleştirmiştir. Tang'in bulguları da, hem öğretmenlerin hem de öğrencilerin büyük çoğunluğunun yabancı dil sınıflarında Çince kullanılması konusunda hemfikir olduklarını göstermektedir(bkz.Ek-4).

Anadilin yabancı dil sinıflarında kullanılması üzerine öğrenci tutumlarını ölçen benzer bir araştırma Yunanlı araştırmacı Prodromou tarafindan gerçekleştirilmiştir (www.teachingenglish.org.uk/think/ methodology/mother_tongue.shtml). Başlangıç seviyesinde (beginner), orta seviyede (intermediate), ve ileri seviyede (advanced) 300 Yunanlı ögrenciye anket uygulanmıştır. Araştırma sonuçları genel olarak incelendiğinde başlangıç seviyesinde olan öğrencilerin \%66'sı, orta seviyede olanların $\% 58$ 'i ve ileri seviyede olanların \%29'u yabancı dil öğretmenlerinin sinıf içerisinde Yunanca konuşmalarının olumlu etkileri olduğu yönünde görüş belirtmişlerdir. Burada dikkat edilmesi gereken bir nokta, öğrencilerin dil becerileri arttıkça anadile olan gereksinimlerinin azalmasıdır. Orta ve ileri seviyedeki öğrenciler daha az seviyelerde anadil kullanımı istemektedir. $\mathrm{Bu}$ bulgu, daha önce bahsedilen "ögrencilerin zaman içerisinde anadile olan bağımlılıklarının kendiliğinden azalacağı görüşü” ile birebir örtüşmektedir. $\mathrm{Bu}$ durumda, yabancı dil sinıflarında anadil kullanımını tabu olarak görmektense, anadilin öğrenmeye olumlu etki yapabileceği yerlerin araştırılması daha yerinde bir adım olabilir.

Gerek şimdiye kadar savunulan fikirleri daha da somutlaştırmak ve gerekse buraya kadar değinilen araştırmalardan daha kapsamlı olduğu için Internet üzerinden yapılan bir araştırmaya yer verilecektir. Yabancı dil ögretiminde anadilin kullanılmasına yönelik, farklı ülkelerden 641 yabancı 
dil öğretmeninin konu hakkındaki görüşleri ve tutumları Tablo 2'de sunulmuştur.

(http://www.teachingenglish.org.uk/talk/vote/vote15_mother_tongue.shtml):

Tablo 2: Yabancı dil sinıflarında anadil her ne pahasına olursa olsun göz ardl mı edilmelidir yoksa yabancı dil ögretiminde faydalı bir referans olabilir mi?

Yabancı dil öğretirken öğrencilerin anadilinin kullanılmasına karşı tutumlarınızı aşağıdaki seçeneklerden hangisi en iyi şekilde açıklamaktadır?

Oylama sonuçları:

F $\%$

1: Sinıfta sadece hedef dili kullanırım $13621 \%$

2: Anadili bazen kullanırım

$37158 \%$

3: Dersin yarısında anadil kullanırım

4: Sıkça anadil kullanırım

$396 \%$

$498 \%$

5: Çoğunlukla anadil kullanırım

$467 \%$

Toplam oy sayıs1: 641

$\mathrm{Bu}$ anketin sonuçlarını yorumlayacak olursak ankete katılan öğretmenlerin \%21'i hiçbir şartla anadilin kullanılmaması gerektiği görüşündedir. \%58'i ise, ki bu çoğunluk anlamına geliyor, anadilin bazen kullanılmasından yana oldukları görüşünü belirtmiştir. Bu sonuç yabancı dil öğretiminde anadilin öğretmenler tarafindan olumlu etkileri olduğunun düşünüldüğü ve dikkatli ve makul seviyelerde kullanılması gerektiği olarak yorumlanabilir. Ankete katılan öğretmenlerin geri kalanı ise (\%21) dersin yarısında veya daha fazlasında anadil kullandıklarını belirtmişlerdir. Son bir genelleme yapılacak olursa, dünyanın farklı köşelerinde farklı seviyelerde ögretmenlik yapan 641 yabancı dil öğretmenin sadece \%21'i "hayır" cevabı verirken, geri kalan \%79'u "evet" cevabını vermiştir. Bu sonuçlar daha önce değinilen araştırma sonuçlarıyla da örtüşmektedir.

Aynı ankete katılan öğretmenlerden bazılarının, konu hakkında yazdıkları yorumlardan birkaç örnek vermek yerinde olacaktır. Örneğin, Polonya'dan yorum yazan bir öğretmen ilk başlarda Lehçe kullanmadığını ancak bu durumun özellikle başlangıç seviyesindeki öğrencilerin konuyu anlamalarına olumsuz etki yaptığını belirtmiştir. Şu anda ise alt seviyeli gruplarla Lehçe kullandığını ve sonucun daha etkili bir öğrenme ortamı yarattığını düşündüğü görüşünü aktarmıştır. İspanya'dan yorum yazan bir başka öğretmen ise yabancı dil öğretirken anadil kullanmanın gerekli olduğunu düşündügünü ve özellikle dilbilgisi öğretirken anadil kullandığını ve bunun her şeyi daha hızlı ve daha basit yaptığını belirtmiştir. Brezilya'dan 
bir öğretmen ise her zaman hedef dil kullanılmasına inandığını ancak bazen anadil kullanımının gerçekten faydalı olabildiği yorumunu yapmıştır. Aslında yaptığı şu yorumla konuyu özetlemektedir; "eğer yabancı dil sınıflarında ana dil kullanılmasının gerçek nedenlerini biliyorsanız, anadil kullanmak bir tabu değildir, bilinçli olmak anahtar kelimedir" (http://www.teachingenglish.org.uk/talk/vote/vote15_mother_tongue.shtml).

Hem bir dil öğrenicisi hem de öğreticisi olarak araştırmacının bugüne kadar edindiği kişisel deneyimler, mantıklı ve belli seviyede anadil kullanımının yabancı dil öğrenimine ve öğretimine yardımcı olabileceğini ve hatta daha etkili yapabileceğini göstermektedir. Ancak, anadil kullanımının önemi yabancı dil öğretim yöntemleri literatüründe göz ard1 edilen bir konudur. $\mathrm{Bu}$ göz ardı edilmişlik, yaygın olarak kabul edilen ana dil kullanımının sınıf içerisinde yasaklanması görüşüyle birleşince bir çok yabancı dil öğretmenini bu konuda bir ikileme sürüklemektedir; sınıfta ögrencilerin ana dillerini kullanmalı mıyım?, sınıfta ögrencilerin ana dillerini kullanmalarına izin vermeli miyim? Konu hakkında Türkiye'de yapılmış bir araştırmaya rastlanmamıştır. Bu bağlamda değerlendirildiğinde, bu araştırmanın konuya ilgi uyandıracağı ve benzer araştırmalara öncülük edeceği düşünülmektedir. Yapılacak olan yeni araştırmaların da katkısıyla Türkiye'deki yabancı dil öğretim yöntemlerine yeni bir bakış açısı kazandırılarak, öğretmen kaygıları giderilebilir.

\section{YÖNTEM}

\section{Amaç}

Yapılan araştırma şu sorulara cevap bulma amacını taşımaktadır:

1. Türkçe, yabancı dil derslerinde kullanılmalı mıdır? Eğer, kullanılmalıysa bu hangi sıklıkta ve hangi amaçlar doğrultusunda yapılmalıdır?

2. Öğrencilerin ve öğretmenlerin, yabancı dil derslerinde Türkçe kullanımına ilişkin tutum ve görüşleri nelerdir?

\section{Evren ve Örneklem}

Burdur Anadolu Öğretmen Lisesi çalışmanın evreni olarak belirlenmiştir. Çalışmaya dahil edilen örneklem grubu ise bu okuldaki 9 . sınıf (Lise 1) öğrencileri ve aynı okulda görev yapan İngilizce öğretmenleridir. Çalışmaya toplam 148, 9. sınıf öğrencisi ve 10 İngilizce öğretmeni dahil edilmiştir. Öğrencilerin İngilizce bilgi seviyeleri orta (intermediate) düzeydedir. Öğretmenlerin mesleki deneyimleri ise 4 yıl ile 15 y1l arasında değişmektedir. 


\section{Veri Toplama Yöntemi ve Analiz}

Öğrencilere ve öğretmenlere eğitim öğretim yılının, ikinci döneminin sonunda bir anket uygulanmıştır. Uygulanan anketlerin geri dönüş oranı \%100'dür. Uygulanan anket sorularında, daha önce değinilen Schweers (2003) ve Tang'in (2002) anket sorularından da faydalanılmıştır. Öğrencilere uygulanan anket $(E k-1)$ toplam yedi sorudan oluşmaktadır. Öğretmenlere uygulanan anket ise (Ek-2) toplam 3 sorudan oluşmaktadır.

Çalışmada SPSS 11 paket programı kullanılmıştır. Her öğrenciye ve öğretmene ayrı ayrı katılımcı numarası verilerek sonuçlar bilgisayara işlenmiştir. Elde edilen veriler, betimsel istatistik (descriptive analysis) yöntemi kullanılarak analiz edilmiş ve genel sonuçlara ulaşılmıştır.

\section{BULGULAR VE YORUM}

Dağıtılan anketlerin analizi sonucu elde edilen bulgular Tablo 3'de sunulmaktadır. Sonuçlar Tablo 3'de birlikte ele alınmış ve anında karşılaştırma yapma olanağı tanınmıştır. Tablo 3'de yer alan 2., 5., 6., ve 7. sorular sadece öğrenci anketinde yer almıştır.

Tablo 3: Türkçe'nin Yabancı Dil Sınıflarında Kullanılması Üzerine Yapılan Anket Sonuçları*

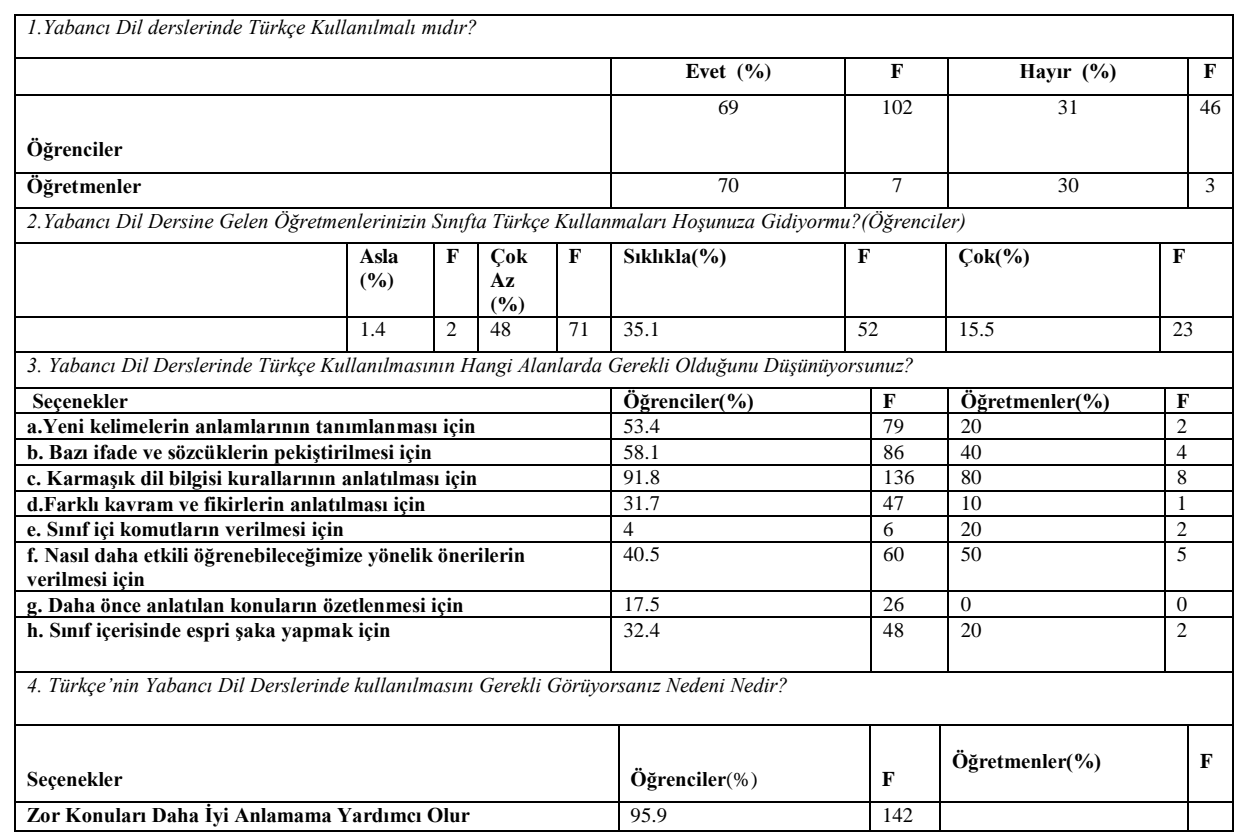

*3. ve 4. sorular için birden fazla seçeneğin işaretlenmesine izin verilmiştir. Bu nedenle bu soruların genel toplamları \% 100 'den ve toplam sayıdan fazla çıkmaktadır. 


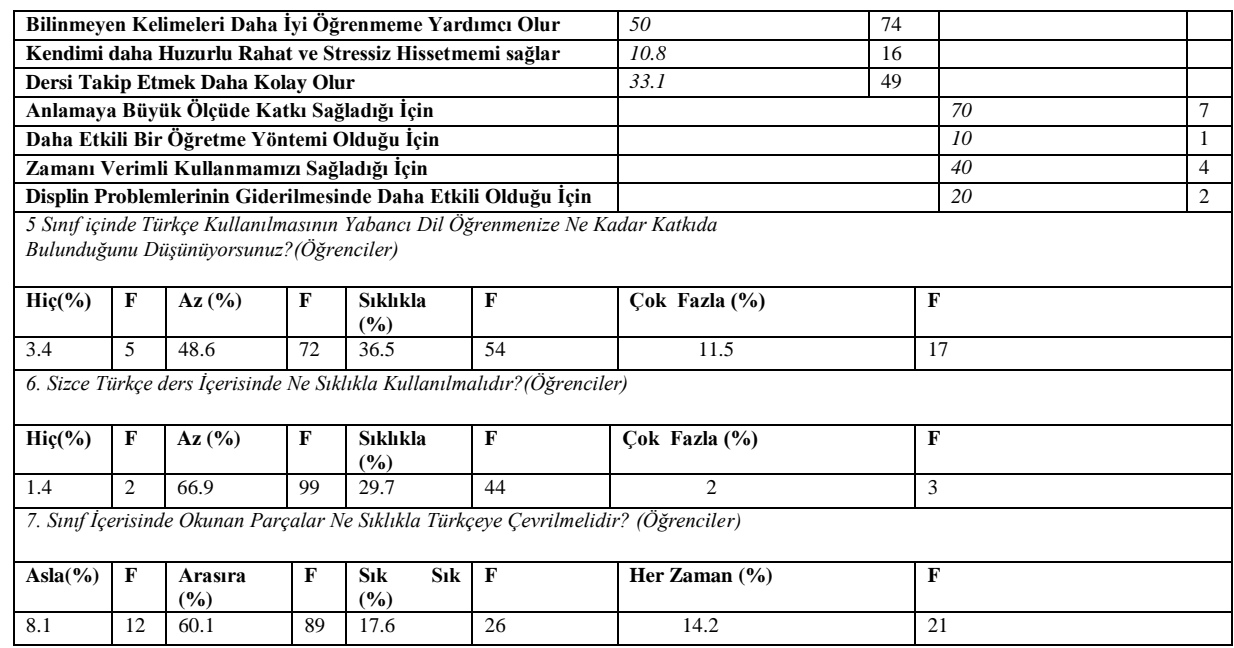

Birinci soruya verilen cevaplar, öğretmen $(\% 70 / \mathrm{f}=7)$ ve öğrencilerin (\%69/f=102) çoğunluğunun yabancı dil derslerinde Türkçe kullanılması gerektiğini düşündüğünü göstermektedir. Bu oranlar daha önce değinilen Tang'in (2002) Çinde yaptığı araştırmada \%72 ve \%70 olarak, Schweers'in (2003) İspanyada yaptığ 1 araştırmada ise $\% 100$ ve \%88 olarak saptanmıştır. Özellikle, burada sonuçları belirtilen araştırma sonuçları ile Tang'in (2002) araştırma sonuçları neredeyse birbirinin aynıdır(bkz.Ek 4).

İkinci soruya verilen cevaplar incelendiğinde ise, öğrencilerin çok büyük bir çoğunluğu $(\% 98,6$ 's1/f=146) yabanc1 dil öğretmenlerinin sınıfta farklı sıklıklarla Türkçe konuşmalarından hoşlandıklarını belirtmişlerdir. Bu oran Tang'in (2002) araștırmasında \%97, Schweers'in (2003) araştırmasında ise \%100 olarak karşımıza çıkmaktadır. $\mathrm{Bu}$ sonuçlar, yabancı dil öğretmenlerinin sınıfta farklı sıklıklarla anadil kullanmalarının öğrencilerin hoşuna gittiğini ve onları motive ettiğini göstermektedir.

Üçüncü soruya verilen cevaplar incelendiğinde; öğrencilere göre, Türkçe en çok karmaşık dilbilgisi kurallarının anlatılması $(\% 91,8 / \mathrm{f}=136)$ ve bazı sözcük ve ifadelerin pekiştirilmesi için $(\% 58,1 / \mathrm{f}=86)$ gerekli görülmüştür. Dikkat çeken bir başka husus ise hiçbir öğrencinin bu sorunun 8 seçeneğinden hiçbirine asla yanıtı vermemiş olmasıdır. 1. soruda Türkçe kullanılmamalı diyen \%31'lik ( $\mathrm{f}=46)$ öğrenci kitlesi bile birkaç seçenek işaretlemiştir. Türkçe kullanılmasının en az gerekli olduğu durumlar ise; daha önce anlatılan konuların özetlenmesi $(\% 17,5 / \mathrm{f}=26)$ ve sınıf içi komutların verilmesi $(\% 4 / \mathrm{f}=6)$ amacıyla olması gerektiği belirtilmiştir. Aynı soruya verilen öğretmen cevaplarına göre ise, Türkçe en çok karmaşık dilbilgisi kurallarının anlatılması için $(\% 80 / \mathrm{f}=8)$ gerekli görülmektedir. $\mathrm{Bu}$ amaç hem öğrenciler hem de öğretmenler için en gerekli görülen amaçtır ve 
bu bulgu diğer araştırma sonuçları ile birebir örtüşmektedir. Öğretmenlerin ikinci önceliği ise, \%50 (f=5) ile nasıl daha etkili ögrenme olacă̆ına yönelik önerilerin verilmesi için Türkçe kullanılmasıdır. Araştırmaya katılan öğretmenler, Türkçe'nin daha önce anlatılan konuların özetlenmesi için asla kullanılmaması gerektiğini belirtmişlerdir.

Türkçe kullanılmasının nedenleri hakkındaki 4. soruya verilen cevaplar incelenecek olursa; öğrencilerin çok büyük bir bölümü $(\% 95,9 / \mathrm{f}=142)$ zor konuları daha iyi anlamalarına yardımcı olduğunu ve yarısı $(\% 50 / \mathrm{f}=74)$ bilinmeyen kelimeleri daha iyi öğrenmelerine yardımcı olduğu görüşünü belirtmiştir. Öğretmenlerin birinci önceliği ise, anlamaya büyük ölçüde katk1 sağladığı görüşüdür $(\% 70 / \mathrm{f}=7)$. Ikinci öncelik olarak ise, $(\% 40 / \mathrm{f}=4)$ zamanı verimli kullanmamızı sağladığı görüşü belirtilmiştir. Bu görüşte olanlar, her ne kadar yarıdan biraz az da olsa anadilin zaman kazandırıcı özelliği aslında herkes tarafindan bilinmektedir.

Beşinci soruya verilen cevaplar incelendiğinde, öğrencilerin \%3,4'ü ( $\mathrm{f}=5$ ) sınıf içerisinde Türkçe kullanılmasının yabancı dil öğrenmelerine hiç katkıda bulunmadığını belirtmişlerdir. Geri kalan \% 86,6's1 (f=143) ise Türkçe'nin farklı oranlarda öğrenmelerine katkı sağladığını belirtmişlerdir. Bunlardan \%48,6's1 (f=72) ,,az “ seçeneğini işaretlemiştir.

Altıncı soruya verilen cevaplar incelendiğinde benzer bir durum ortaya çıkmaktadır. Öğrencilerin \%1,4'ü $(\mathrm{f}=2)$ ders içinde Türkçe'nin hiç kullanılmaması gerektiğini düşündüklerini belirtmişlerdir. Geri kalan \%98,6's1 (f=146) ise farklı aralıklarla Türkçe kullanılmalıdır görüşündedir. Bunların \%66,9'u ( $\mathrm{f}=99)$, , $a z$ " seçeneğini işaretlemişlerdir.

Yabancı dil öğretmenlerinin bir ders tekniği olarak zaman zaman çeviri alıştırmalarına başvurdukları ve hatta ders kitaplarının birçoğunda bu tarz alıştırmaların yer aldığı bilinmektedir. Bu konuda öğrenci düşüncelerinin sorulduğu 7. soruya öğrencilerin $\% 8$ 'i $(\mathrm{f}=12)$ asla cevabını vermişleridir. Geri kalan büyük çoğunluk ise $(\% 92 / \mathrm{f}=136)$ farklı sıklıklarla bu yönteme başvurulmasının gerekli olduğunu belirtmiştir. En çok işaretlenen seçenek ise \%60'la ( $\mathrm{f}=89$ ) arasıra cevabıdır. Buda aşırıya kaçmamak koşuşuyla öğrencilerin çeviri alıştırmalarından hoşlandıklarını ve olumlu yönde etkilendiklerini göstermektedir.

\section{TARTIŞMA VE SONUÇ}

$\mathrm{Bu}$ araştırmada ortaya konulan sonuç ve düşüncelere tüm yabancı dil öğretmenlerinin tamamıyla katılması, en azından ilk bakışta, pek de olası olmayabilir. Bazıları, özellikle yabancı dil öğrencilerinin yabancı dil dersinde mümkün olan en üst seviyede hedef dile ihtiyaçlarının olduğunu söyleyebilir. Bazıları ise sinıfta sadece hedef dil kullanılmasının, ögrencilerin hedef dilde iletişim kurmalarına olanak sağlayacağını ve bu 
durumun dil becerilerini geliştireceğini söyleyebilir. Elbette, hedef dilin, yabancı dil sınıflarında birincil iletişim aracı olması gerektiği görüşüne araştırmacı da katılmakta ve öğrencilerin mümkün olan en üst seviyede hedef dil duymalarına ve kullanmalarına olanak sağlamanın gerekliliğinin bilincindedir. Ancak, daha önce belirtildiği gibi tek dilli yaklaşımlar (monolingual approaches) cazibesini yitirmeye başlamıştır ve yabancı dil sınıflarında anadilin yasaklanmasından çok, rolünün farkına varılması gerektiği görüşü ön plana çıkmaya başlamıştır. Kaldı ki, yapılan araştırma sonuçları bu doğrultudadır.

Yapılan bu araştırmanın sonuçları, yabancı dil sınıflarında sınırlı miktarda ve mantıklı anadil kullanımının ögrencilerin İngilizce ile olan iletişimlerini azaltmadığını, aksine öğretme ve öğrenme aşamalarında kolaylaştırıcı bir rolü olabileceğini göstermektedir. Araştırmaya katılan öğrenci ve öğretmenlerin büyük bir çoğunluğu Türkçe'nin yabancı dil derslerinde kullanılması gerektiğini belirtmişlerdir. $\mathrm{Bu}$ sonuç, anadilin yabancı dil sınıflarındaki yerinin abartılması ve çok daha fazla kullanılması gerektiği anlamına gelmemelidir. Daha çok, yabancı dil öğretmenlerinin düşüncelerini yıllardır meşgul eden bazı yanılgıları açıklığa kavuşturmaktadır; sınıfta anadile ihtiyaç olduğu zaman kullanmalı mıyım? çok sık rastladığımız "yabancı dil sınıfinda asla anadil konuşulmamalıdır" prensibi doğru mudur? gibi. Elde edilen araştırma sonuçlarının, anadilin yabancı dil sınıflarındaki rolü hakkında daha çok kişiyi bilinçlendireceği ve bu alanda daha fazla araştırma yapılmasını teşvik edeceği düşünülmektedir.

Yapılan araştırma sonuçlarına dayanarak, anadilin yabancı dil sınıflarında en etkili olabileceği yerleri ve anadil kullanmanın temel nedenlerini şu şekilde sıralamak mümkündür:

- Karmaşık dilbilgisi kurallarının öğretilmesi için

- Bazı sözcük ve ifadelerin pekiştirilmesi ve anlamlarının öğretilmesi için

- Özellikle başlangıç (beginner) seviyesinde olan öğrenciler söz konusu olduğunda, anadilin yasaklanmasının pratik olarak çok da mümkün olmadığ 1 için

- Anlamaya ve öğrenmeye katkı sağladığı için

- Zaman kazandırdığı için

Son olarak ise değinilmek istenen paralel bir konu daha bulunmaktadır. $\mathrm{O}$ da, yabancı dil ders kitaplarının tek dilli yaklaşıma (monolingual approach) göre mi, yoksa iki dilli yaklaşıma (bilingual approach) göre mi hazırlanması gerektidiğidir. Gerek MEB'na bağlı okullardaki tüm yabancı dil ders kitaplarının ve gerekse diğer yabancı dil kitaplarının büyük bir 
çoğunluğunun tek dilli yaklaşıma göre hazırlandı̆̆ 1 görülmektedir. Ancak, Jin (2003) Çinde ,yenilikçi iki dilli ögretim metodu“ (innovative bilingual teaching method) adı verilen bir yöntemin, son y1llarda uygulamaya konulduğunun ve iki dilli yaklaşıma göre hazırlanan ders kitaplarının yabancı dil öğretiminde başarıyı da beraberinde getirdiğini iddia etmektedir.

İki dilli öğretim metodunun 3 önemli avantajı olduğu savunulmaktadır. Bunlardan ilki, yabancı dildeki kelimelerin anlamlarının anında görülerek anlam tahmini ile vakit harcanmamasıdır. Anadilin kullanılması sonucu, anlam yabancı dil öğreniminin ilk aşamalarında hemen anlaşılır ve bu durum öğrenmenin gerçekleşmesini garanti altına alır. İkincisi, iki dilli yöntem öğrencilerin ana dillerini de geliştirmelerine olanak tanır ve iki dilin sürekli karşılaştırılması sonucu yabancı dildeki yeni kelimeler ve temel yapılar içselleştirilmiş olur ve iki dil arasında kavramsal bir bağ kurulmasına yardımcı olur. Üçüncü olarak ise anadil kullanımı yabancı dil öğreniminin ilk aşamalarında doğal bir eğilim olan anlam edinimi gereksinimini kolaylaştırır. Küçük yaşlardaki öğrenciler henüz olgun olmadıkları için tek dilli yöntemin uygulamalarını ve bu yönde hazırlanan kitapları cazip bulmayıp, anlayamadıkları bu yeni dilden uzaklaşabilirler. Sonuç olarak, anadilin yabancı dil sınıflarında kullanılması özellikle erken yaşlardaki yabanc1 dil öğrencilerinin öz güvenlerinin ve motivasyonlarının artırılmasında önemli bir rol oynayabilir.

Elbette bu konu gerek eğitimcilerin gerekse MEB yetkililerinin temkinle yaklaşması gereken bir noktadır. Başarılı sonuçları olduğu iddia edilen bu metot hakkında yeni araştırmaların yapılması gerekmekte ve olumlu sonuçlar elde edilecek olursa özellikle başlangıç (beginner) seviyesinde olan, ilköğretim 1. kademede okutulan ders kitaplarında bir yaklaşım değişikliğine doğru gidilmesi gerekebilir. Örneğin, yabancı dil alıştırma kitaplarında (workbooks) yer alan "fill in the blanks with the appropriate form of the verbs in paranthesis, choose the appropriate answer from the following list, match the pictures with the letters" tarzindaki komutların yanına parantez içerisinde Türkçe açıklamalarının en azından ilk başlarda yazılmasının değerlendirilmesi gibi. Böylece yabancı dile yeni başlayan bir öğrenci, evde ders çalışırken ne zaman ne yapması gerektiğini daha iyi anlayacak ve zamanını daha etkili bir şekilde geçirmiş olacaktır. Ancak bu tarz bir adım atılmadan önce, iki dilli ögretim metodu ile yazılan ders kitaplarının dil öğrenmeye yardımc1 olup olmadığı konusunda da bilimsel araştırma yapılmasına ihtiyaç vardır. Yapılacak olan araştırmaların 1şığı altında durum değerlendirmesi yapılıp gerekiyorsa düzenleme yapilabilir. 


\section{KAYNAKLAR}

Auerbach, E. (1993). Reexaming English only in the ESL classroom. TESOL Quarterly 27(1), 9-32.

Deller, S. \& Rinvolucri, M. (2002). Using the mother tongue; making the most of learner's language. Delta Publishing: English Teaching Professional.

Dörnyei, Z. \& Kormos, J. (1998). Problem-solving mechanisms in L2 communication: A psycholinguistics perspective. Studies in Second Language Acquisition, 20(3), 349-385.

http://www.teachingenglish.org.uk/talk/vote/vote15 mother tongue.shtml

Jin, Z. (2003). New wine in an old bottle: innovative EFL classrooms in China. IATEFL, 172(2), 34-42.

Krashen, S. (1981). Second language education and second language learning. Oxford: Pergamon.

Medgyes, P. (1994). The non-native teacher. London: Macmillan Pub. Ltd.

Nation, I.S.P. (1990). Teaching and learning vocabulary. New York: Newburry House.

Nunan, D. \& Lamb, C. (1996). The self-directed teacher. Cambridge: Cambridge University Press.

Prodromou, L. L. [online] Retrieved on 15-August-2006, at URL: www.teachingenglish.org.uk/think/methodology/mother tongue.shtml

Richards, J.C. \& Rodgers, T.S. (1995). Approaches and Methods in Language Teaching. Cambridge: Cambridge University Press.

Rinvolucri, M. (2001). Modern tongue in the foreign language classroom. Modern English Teacher, 10, 41-44.

Schweers, W.Jr. (2003). Using L1 in the L2 classroom. English Teaching Forum, 41 (4), 34-7.

Tang, J. (2002). Using L1 in the English classroom. English Teaching Forum, 40 (1), 36-43. 


\section{EK 1:}

\section{Öğrencilere Uygulanan Anket Formu}

Sevgili Öğrenci,

$\mathrm{Bu}$ anket yabancı dil derslerinde Türkçe'nin kullanımı yolunda sizin görüşlerinizi ölçmek amacıyla hazırlanmıştır. Ankete verecek olduğunuz cevaplar sadece araştırma hedefleri doğrultusunda kullanılacak ve gizli tutulacaktır.

Katıldığınız için teşekkürler.

Not: Katıldığınız cevabı daire içine alınız. 3. ve 4. sorularda birden fazla şık işaretleyebilirsiniz.

1. Yabancı dil derslerinde Türkçe kullanılmalı mıdır?
a) Evet
b) Hayır

2. Yabancı dil dersine gelen öğretmenlerinizin sınıfta Türkçe kullanmaları hoşunuza gidiyor mu?
a) asla
b) çok az
c) s1klıkla
d) çok

3. Yabancı dil derslerinde Türkçe kullanılmasının hangi alanlarda gerekli olduğunu düşünüyorsunuz?
a) Yeni kelimelerin anlamlarının tanımlanması için
b) Bazı ifade ve sözcüklerin pekiştirlmesi için
c) Karmaşık dil bilgisi kurallarının anlatılması için
d) Farklı kavram ve fikirlerin anlatılması için
e) Sınıf içi komutların verilmesi için
f) Nasıl daha etkili öğrenebileceğimize yönelik önerilerin verilmesi için
g) Daha önce anlatılan konuların özetlenmesi için
h) Sınıf içerisinde espri şaka yapmak için
i) Bunların dışında Belirtmek istediğiniz varsa lütfen yazınız 
4. Eğer Türkçenin yabancı dil derslerinde kullanılmasını gerekli görüyorsanız nedeni aşağıdakilerden hangisi ya da hangileridir?
a) Zor Konuları Daha İyi Anlamama Yardımcı Olur
b) Bilinmeyen Kelimeleri Daha İyi Öğrenmeme Yardımcı Olur
c) Kendimi daha Huzurlu Rahat ve Stressiz Hissetmemi sağlar
d) Dersi Takip Etmek Daha Kolay Olur

e) Bunların dışında görüşleriniz varsa lütfen belirtiniz.

5. Sınıf içinde Türkçe Kullanılmasının Yabancı Dil Öğrenmenize Ne Kadar Katkıda Bulunduğunu Düşünüyorsunuz?
a) hiç
b) az
c) S1kl1kla
d) çok fazla

6. Sizce Türkçe ders içerisinde ne sıklıkla kullanılmalıdır?
a) hiç
b) az
c) S1klıkla
d) çok fazla

7. Sınıf içerisinde okunan parçalar ne sıklıkla Türkçeye çevrilmelidir?
a) asla
b) ara sira
c) sik sik
d) her zaman 
EK 2:

Öğretmenlere Uygulanan Anket Formu

Sevgili meslektaşım,

Bu anket yabancı dil derslerinde Türkçe'nin kullanımı yolunda sizin görüşlerinizi ölçmek amacıyla hazırlanmıştır. Ankete verecek olduğunuz cevaplar sadece araştırma hedefleri doğrultusunda kullanılacak ve gizli tutulacaktır.

Katıldığınız için teşekkürler.

Not: Katıldığınız cevabı daire içine alınız. 2. ve 3. sorularda birden fazla şık işaretleyebilirsiniz.

1. Yabancı dil derslerinde Türkçe kullanılmalı mıdır?
a) Evet
b) Hayır

2. Yabancı dil derslerinde Türkçe kullanılmasının hangi alanlarda gerekli olduğunu düşünüyorsunuz?

a) Yeni kelimelerin anlamlarının tanımlanması için

b) Bazı ifade ve sözcüklerin pekiştirlmesi için

c) Karmaşık dil bilgisi kurallarının anlatılması için

d) Farklı kavram ve fikirlerin anlatılması için

e) Sınıf içi komutların verilmesi için

f) Nasıl daha etkili öğrenebileceğimize yönelik önerilerin verilmesi için

g) Daha önce anlatılan konuların özetlenmesi için

h) Sınıf içerisinde espri şaka yapmak için

i) Bunların dışında Belirtmek istediğiniz varsa lütfen yazınız.

3. Eğer Türkçenin yabancı dil derslerinde kullanılmasını gerekli görüyorsanız nedeni aşağıdakilerden hangisi ya da hangileridir?

a) Anlamaya Büyük Ölçüde Katkı Sağladığı İçin

b) Daha Etkili Bir Öğretme Yöntemi Olduğu İçin

c) Zamanı Verimli Kullanmamızı Sağladığı İçin

d) Displin Problemlerinin Giderilmesinde Daha Etkili Olduğu İçin

e) Farklı görüşleriniz varsa lütfen belirtiniz 
EK 3*:

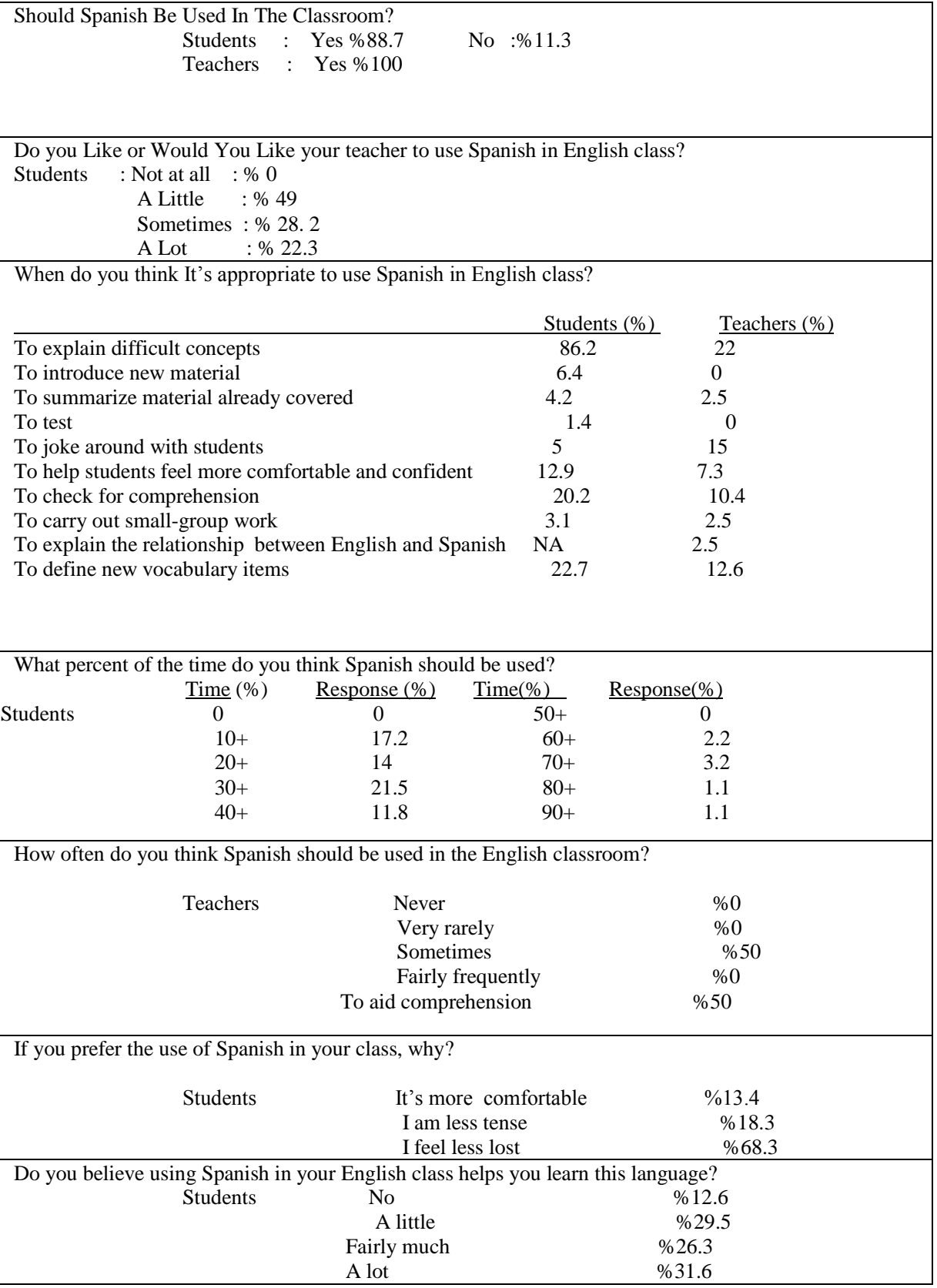

* Kaynak : Schweers, 2003: 36. 
Ek:4*

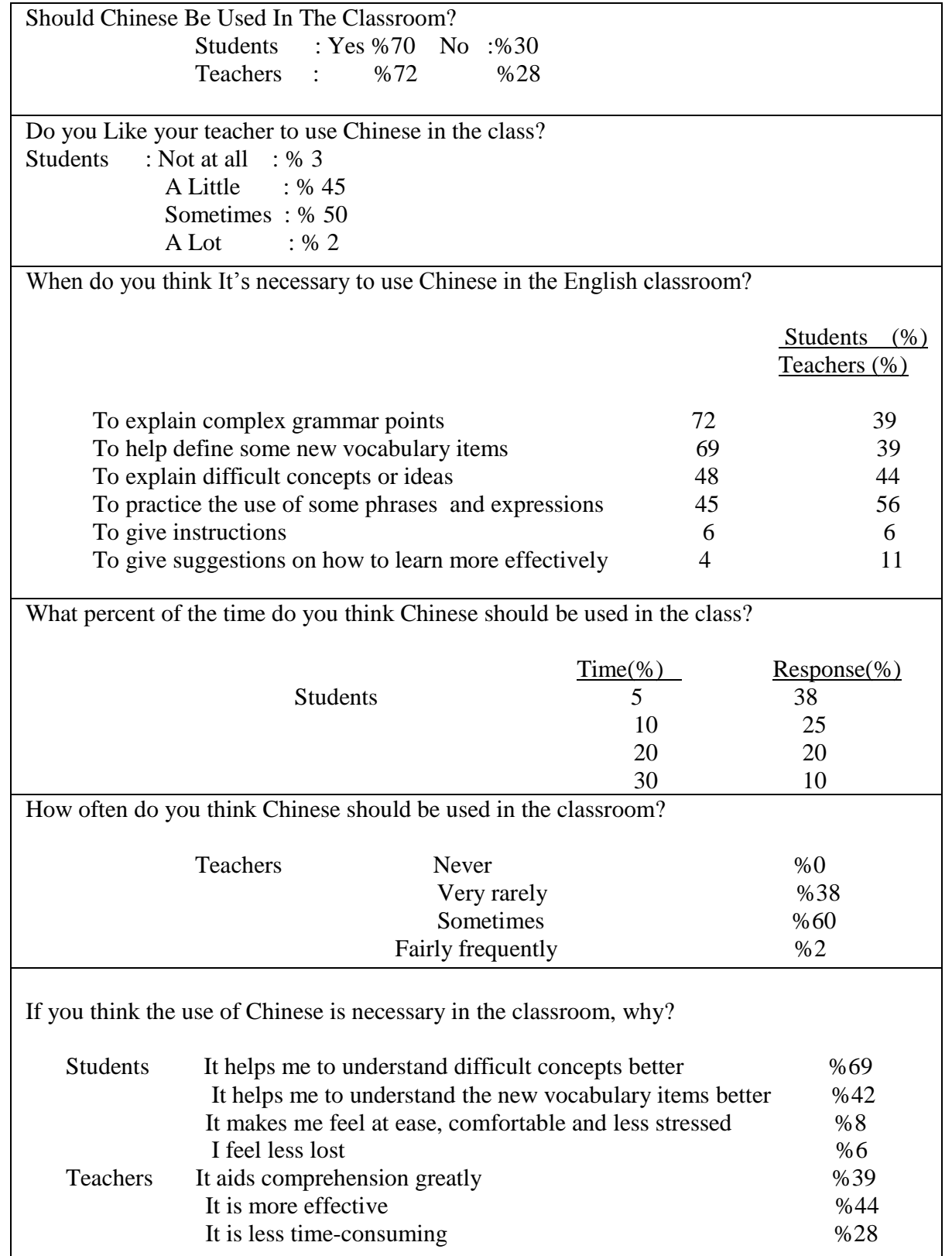

* Kaynak : Tang, 2002: 40. 